\title{
The role of the clinical nurse specialist in haemoglobinopathies
}

\section{Bernadette Hylton}

\section{University College London Hospitals NHS Foundation Trust, London, UK}

The role of the Clinical Nurse Specialist (CNS) is an everdeveloping role that is integral in the care of individuals with haemoglobinopathies.

Haemoglobinopathies are complex disorders that require specialist knowledge to deliver the very best care. In order to offer the best possible patient centred care, the CNS is required to be a constant member of the team, who practises at the highest stan- dard and promotes independence and the expert patient. The CNS supports and challenges patients and members of the multi-disciplinary team to ensure the best possible outcome.

This talk highlights the importance of the CNS role and the vital aspects of the role that a CNS should adopt, develop and improve upon.
Correspondence: Bernadette Hylton, University College London Hospitals NHS Foundation Trust, London, UK

This work is licensed under a Creative Commons Attribution 4.0 License (by-nc 4.0).

(C) Copyright B. Hylton, 2018

Licensee PAGEPress, Italy

Thalassemia Reports 2018; 8:7488

doi:10.4081/thal.2018.7488 